\title{
Influence of the Underwater Structures upon the Sediment Transport in the Coastal Zone
}

\author{
D. V. Korzinin*, Ya. V. Saprykina \\ Shirshov Institute of Oceanology, Russian Academy of Sciences, Moscow, Russian Federation \\ *e-mail: korzinin2000@mail.ru
}

\begin{abstract}
Significantly deepened coastal structures regarded as wave breakers can influence both on the wave and sediment transport parameters in the coastal zone. The wave breakers applied at present are placed not deep and this factor negatively influences navigation and water exchange between the coastline zone and the open sea. Optimal location of the underwater structure permits to arrive at a solution of the beach erosion problem with the purpose of preserving aesthetic attraction of the coast. Due to numerical modeling using the Xbeach model, studied is the influence of the significantly deepened solid and impermeable bar upon the sediment transport depending on different wave parameters and the bar location relative to the coastline. The applied ratios between the parameters of waves and underwater structure provided the most effective wave height and period decrease. Changes in the sediment transport at various locations of a bar relative the coastline are studied. It is revealed that presence of the underwater bar promotes double reduction of the offshore sediment transport. It is shown that the highest effect in reducing the coast erosion (in case the underwater bar is present) is achieved for the waves whose steepness exceeds 0.04 . Location of the bar closer to the coast results in the offshore sediment transport decrease for the flat waves and increase - for the steep ones. The offshore sediment transport can be minimized in case the underwater bar position is such that the waves passing over it do not break down, bur remain on the verge of breaking.
\end{abstract}

Keywords: underwater structures, wave transformation, wave steepness, sediment transport, coastal erosion.

Acknowledgements: the research is carried out within the framework of the State Order No. 0149-2018-0015.

For citation: Korzinin, D.V. and Saprykina, Ya.V., 2018. Influence of the Underwater Structures upon the Sediment Transport in the Coastal Zone. Physical Oceanography, [e-journal] 25(5), pp. 359-367. doi:10.22449/1573-160X-2018-5-359-367.

DOI: 10.22449/1573-160X-2018-4-359-367

(C) 2018, D. V. Korzinin, Ya. V. Saprykina

(C) 2018, Physical Oceanography

\section{Task setting and methods}

Bottom and coast erosion under the action of storm waves is one of the main problems in the protection of coastal zone facilities. Waves propagating over an inclined bottom and decreasing the depth of water under the influence of nonlinear processes transform, change their shape and become asymmetric, which leads to their collapse. The collapse of waves can contribute to termination of the sediment flow directed towards the coast, moving the bottom material towards the sea with compensational countercurrent and catastrophic erosion of the bottom. Underwater structures, for example, in the form of bars, affect the nature of the wave transformation above them and, thereby, the intensity of the wave energy dissipation in the swash zone and the amount of material carried towards the sea.

Underwater wave breakers, used in present-day practice, as a rule, have a small depth (not more than $0.75 \mathrm{~m}$ according to SP 277.1325800.2016). It has negative effect on shipping and environmental aspects of coastal zone development, such as the aesthetic appeal of the coast and water exchange between the shallow water area and outer part of the water area. An analysis of the experience of using underwater structures with a depth of 0.5 to $1.5 \mathrm{~m}$ relative to the water level on the USA, Japan, Italy and Australia coasts showed that erosion was observed in 7 out of 10 considered cases [1]. This fact proves that the influence 
of the underwater structure on the transformation of the waves and the subsequent wave transport of sediment is not well understood and, possibly, the location of the underwater structure is of key importance. Through physical experiments (report Delft Hydraulics*, as well as [2, 3]), it was found that a small depth of water above the underwater structure has a greater effect on reducing the height of the wave passing above it than in the case with a significant depth of the structure. Separate studies have shown that with increasing water depth, i.e. greater depth, it is possible to reduce the average period to $25-40 \%[4,5]$.

The study of wave transformation over underwater bars in the wave tray $[6,7]$ and using the SWASH model [8,9] made it possible to determine the optimal combinations of wave and bar parameters the maximum changes in wave height and period take place at. To make the underwater structure an effective coast protection structure, during its installation it is necessary to take into account not only local changes in the parameters of the waves above it, but also scenarios for the subsequent transformation of waves to the shore, minimizing the structure's effect on the coast erosion, i.e. to determine the best location of the structure taking into account the preservation of the aesthetic appeal of the coast.

Within the research carried out, two problems were solved:

1) estimation of the effect of the underwater bar of the selected configuration on the sediment consumption depending on the parameters of the waves;

2) analysis the sediment consumption dependence on the position of the bar relative to the coastline for the selected wave mode. The impermeable underwater bar in both tasks was located on a flat bottom with an average slope of 0.02 and a seashore sediment size of $0.02 \mathrm{~mm}$.

The tasks were solved by the mathematical modeling method using the Xbeach model [10,11]. Suspended sediment transport in the Xbeach model is simulated using the advection-diffusion equation [12]. The morphodynamic model block for estimating the sediment transport estimation uses R. Soulsby and L. van Rein formula [13], taking into account sediment transport taking into account the bed load and suspended load transport.

\section{Discussion of the results obtained}

Solving the first problem, the underwater structure (bar) was located at $5.3 \mathrm{~m}$ depth, had a depth of $2.66 \mathrm{~m}$ (the parameters are given at the bar midpoint) and a length of $28 \mathrm{~m}$ (Fig. 1). The wave regime and bar parameters at which the most effective simultaneous decrease in the wave height and the average period of the waves occur are considered as basic [6-9, 14]. The most effective simultaneous reduction of the wave height (by 36\%) and the average wave period (by 33\%) takes place when the relative length of the structure $L_{\mathrm{bar}} / L=0.57$, where $L_{\mathrm{bar}}$ is the length of the bar, $\mathrm{m}$; $L$ is the wavelength, $\mathrm{m}$, and the relative depth of the structure $d_{\mathrm{bar}} / H s=$ $=0.78$, where $d_{\text {bar }}$ is the depth above the bar, $\mathrm{m} ; H s$ is significant wave height, $\mathrm{m}$.

*Smith, G.M., 2002. AmWaj Island Development, Bahrain: Physical Modelling of Submerged Breakwaters. Report H4087 for OSSIS property Development. Deltares (WL), 35 p. Available at: https://repository.tudelft.nl/islandora/object/uuid:7efcbaeb-4fc4-447f-a4d5-fd5c642af777/datastream/OBJ/download [Accessed: 01 May 2018]. 


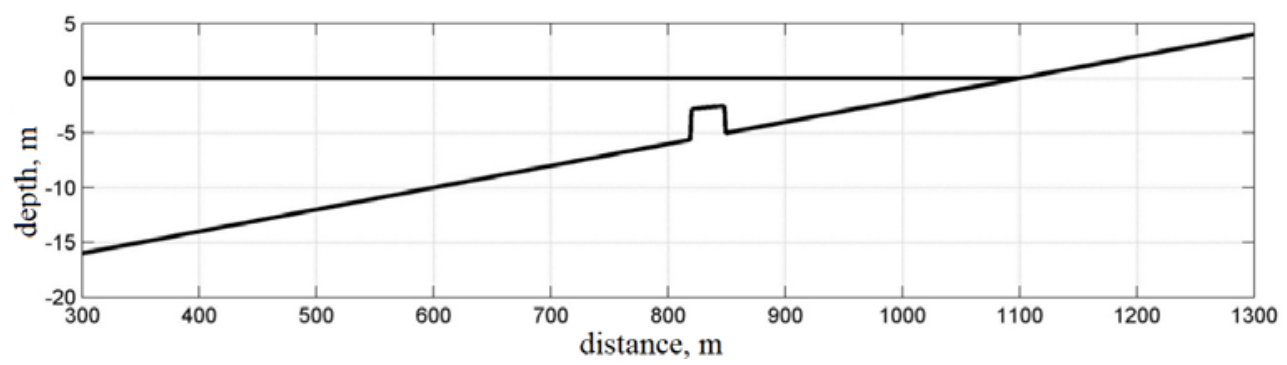

Fig. 1. Underwater structure position on the bottom profile

With these ratios, the parameters of the resulting wave mode are as follows: $H s=3.43 \mathrm{~m}$; average wave period $T=5.61 \mathrm{~s}$; peak wave period $T_{\mathrm{p}}=7.01 \mathrm{~s} ; L=$ $=49.12 \mathrm{~m}$; the steepness of the waves $H_{\mathrm{cp}} / L=0.043$, where $H_{\mathrm{cp}}$ is the average height of the waves.

The underwater bar influence on the sediment transport and the sediment transport variations with changing wave parameters (wave height and period, Table 1) were studied. For comparison, the similar tests without an underwater structure were also carried out.

Table 1

The studied wave regimes to assess the sediment transport parameters at presence of the underwater bar

\begin{tabular}{|c|c|c|c|c|c|}
\hline \multicolumn{6}{|c|}{ Parameters of wave mode with constant wave period } \\
\hline$/ H, \mathrm{~m}$ & $H s, \mathrm{~m}$ & $T, \mathrm{~s}$ & $T_{\mathrm{p}}, \mathrm{s}$ & $L, \mathrm{~m}$ & $(H / L)$ \\
\hline 1.49 & 2.40 & \multirow{7}{*}{5.61} & \multirow{7}{*}{7.01} & \multirow{7}{*}{49.12} & 0.030 \\
\hline 1.70 & 2.75 & & & & 0.035 \\
\hline 1.92 & 3.09 & & & & 0.039 \\
\hline 2.13 & 3.43 & & & & 0.043 \\
\hline 2.34 & 3.78 & & & & 0.048 \\
\hline 2.55 & 4.12 & & & & 0.052 \\
\hline 2.77 & 4.46 & & & & 0.056 \\
\hline \multicolumn{6}{|c|}{ Parameters of wave mode with constant wave height } \\
\hline Hav, m & $H s, \mathrm{~m}$ & $T, \mathrm{~s}$ & $T_{\mathrm{p}}, \mathrm{s}$ & $L, \mathrm{~m}$ & $(H / L)$ \\
\hline \multirow{7}{*}{2.13} & \multirow{7}{*}{3.43} & 4.77 & 5.96 & 35.49 & 0.060 \\
\hline & & 5.05 & 6.31 & 39.79 & 0.053 \\
\hline & & 5.33 & 6.66 & 44.33 & 0.048 \\
\hline & & 5.61 & 7.01 & 49.12 & 0.043 \\
\hline & & 5.89 & 7.36 & 54.16 & 0.039 \\
\hline & & 6.17 & 7.71 & 59.44 & 0.036 \\
\hline & & 6.45 & 8.07 & 64.96 & 0.033 \\
\hline
\end{tabular}


In the process of modelling, the waves affected the bottom profile with an underwater bar for 30 minutes, the simulation results were output once per second. The total consumption of suspended sediment $\left(\mathrm{m}^{2} / \mathrm{s}\right)$ for the entire simulation was estimated. Negative values of sediment flow rate indicate a total sediment discharge towards the sea. The greater the absolute values of this indicator, the greater the amount of sediment carried out of the coastal zone. Irregular waves were set by waves with JONSWAP spectrum parameters - significant wave heights $\left(H_{s}, \mathrm{~m}\right)$, peak frequency $\left(1 / T_{p}, \mathrm{~Hz}\right)$ and spectrum "peak" parameter (gammajsp $\left.=3.3\right)$.

It was obtained that with an increase in the steepness of the waves due to the growth of their height (the period of the waves is the same), the sediment flow towards the sea in the presence of an underwater bar will increase until the slope reaches a value close to 0.04 (Fig. 2, $a$ ). A further increase in the steepness above this value leads to a decrease in sediment discharge towards the sea. At the same time, the discharge of sediments towards the sea on an underwater profile without a bar will have an upward trend with the steepness increasing. At constant wave heights, a decrease in their period (and, accordingly, an increase in steepness) will lead to a decrease in sediment consumption with and without an underwater bar. For all the studied variants it is shown that the sediment consumption in the presence of an underwater bar is always lower than without it. It was revealed that with the studied wave mode, the underwater bar reduces the transfer of material towards the sea twice, and with an increase in steepness due to an increase in wave height, this difference increases.

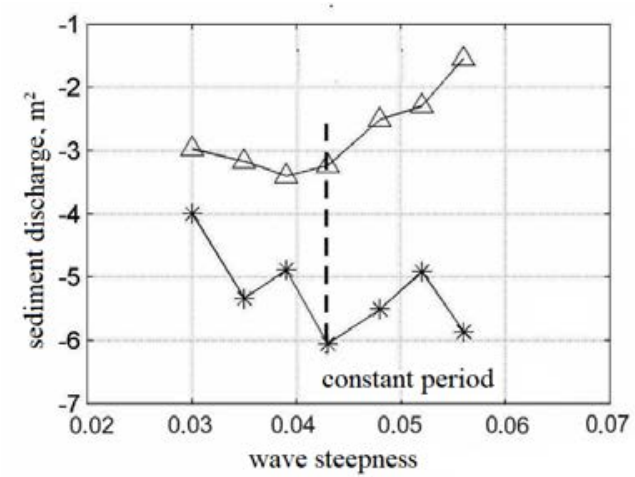

$a$

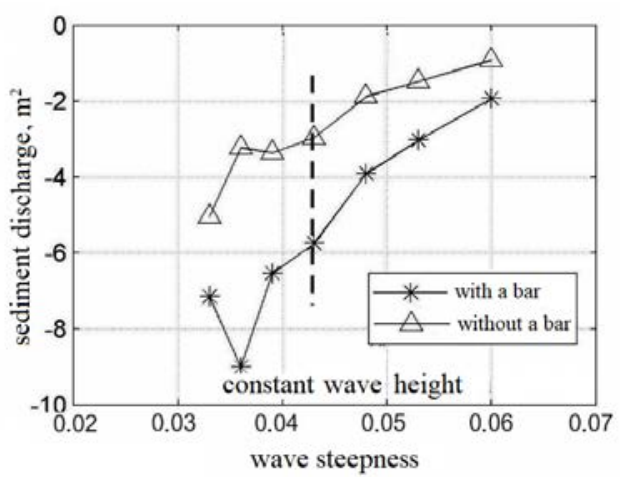

$b$

Fig. 2. Integral values of the suspended sediment total charge in course of a 30 minute long wave impact at variation of the wave height $(a)$ and the period $(b)$ relative to the basic wave regime $(H s=$ $=3.43 \mathrm{~m}, T=5.61 \mathrm{~s}$, dotted line)

When solving the second problem, 20 different positions of impermeable bar and four wave regimes were considered. For all numerical experiments peak wave period $\left(T_{\mathrm{p}}=7.5 \mathrm{~s}\right.$ and $\left.L=87.8 \mathrm{~m}\right)$ and the bar length $(28 \mathrm{~m})$ were the constant parameters. These parameters were selected as optimal from the point of view of obtaining the maximum wave transformation effect above the bar in order to reduce the values of average period. This takes place at $L_{\mathrm{bar}} / L=0.31$. Initial wave parameters selected for modeling are given in Table 2 . 
Wave parameters for numerical modeling

\begin{tabular}{c|c|c|c|c}
\hline Regime number & $H s, \mathrm{~m}$ & $T_{\mathrm{p}}, \mathrm{s}$ & $L, \mathrm{~m}$ & $(H s / L)$ \\
\hline 1 & 1.78 & & & 0.02 \\
2 & 2.33 & 7.5 & 87.8 & 0.027 \\
3 & 2.88 & & & 0.033 \\
4 & 3.43 & & & 0.039 \\
\hline
\end{tabular}

Different positions of bar were characterized by the depth above it $\left(d_{\text {bar }}\right)$ and distance from the bar to the coast $(x)$, (Fig. 3, a). For all bar positions the bar deepening $\left(d_{\mathrm{bar}}\right)$ was equal to the half of the water depth in the site of the structure location. Relative bar deepening was determined as $d_{\text {bar }} / H s$. Bar location relative to the water edge was assessed as a relation of the structure distance from the coast $x$ to the wave length $L(x / L)$. Wave breaking caused by the depth decrease above the bar was determined according to breaking index $\gamma$ by the criterion [15]:

$$
\gamma=0.5+0.4 \tanh \left(33 \mathrm{~s}_{0}\right)
$$

where $\mathrm{s}_{0}=H_{\mathrm{rms}} / L$ is initial wave steepness; $H_{\mathrm{rms}}$ is root-mean-square wave height. According to this dependence, wave breaking takes place at $\gamma>0.8$.
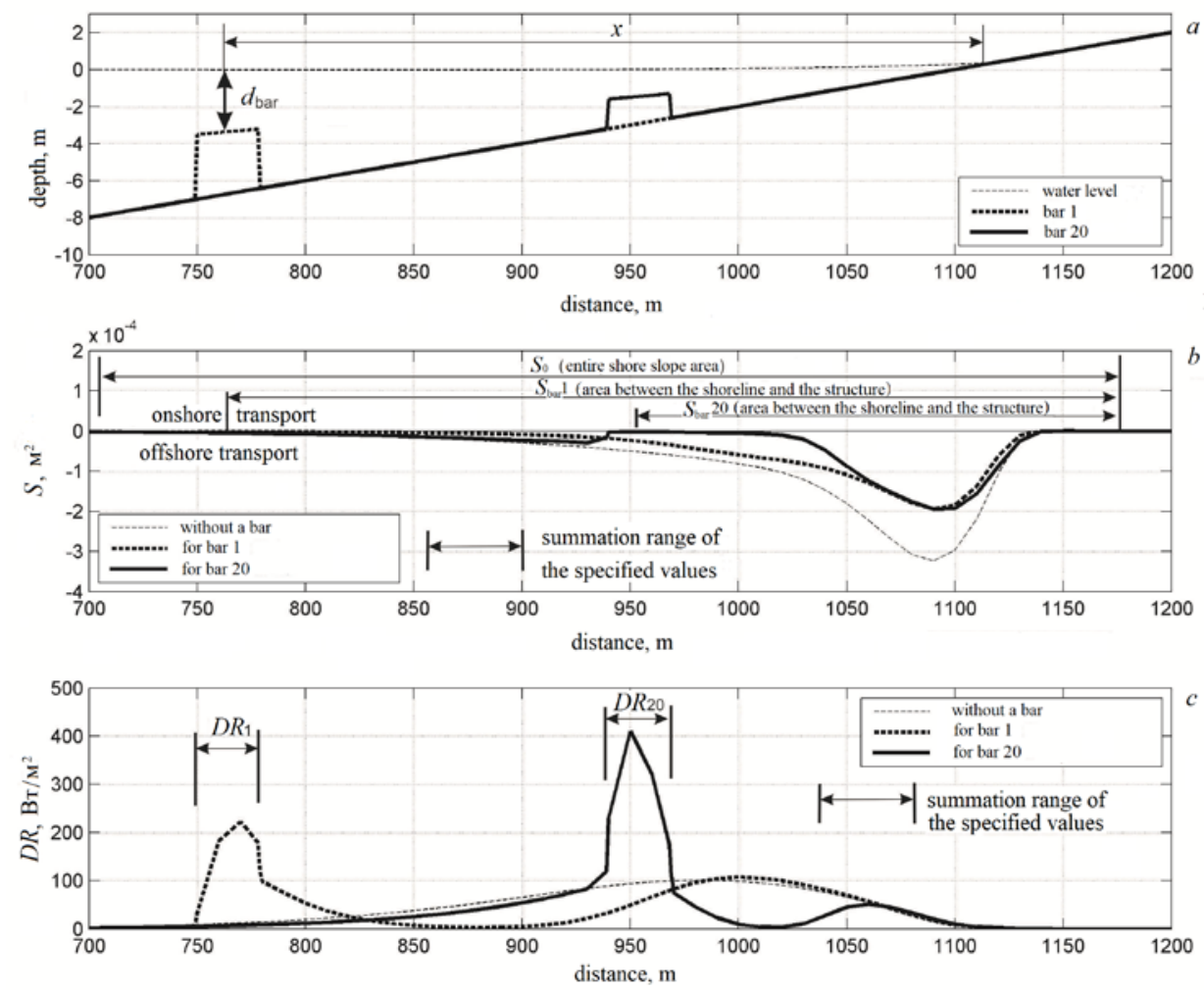

Fig. 3. Bottom topography (a), total values of the sediment transport $(b)$ and the roller energy dissipation (c) for the wave regime 2 at different positions of the bar. DRi is the roller energy dissipation at different positions of the bar 
Total sediment transport at the presence of submarine bar $\left(S_{\mathrm{bar}}\right)$ was calculated as a sum of bed load and suspended sediments. Wave energy variations at the wave transformation above the bar were taken into account on the basis of variation of roller energy dissipation $\left(D R_{\mathrm{bar}}\right)$ values. In Fig. $3, b$ and $c$ the principle of determination of total sediment transport and roller energy dissipation values depending on the bar position is represented.

The main purpose of the study was to clarify how the relative distance from the coast, relative depth above the bar and the intensity of wave energy dissipation affect the amount of sediments transported in the coastal area, particularly on the fixed-length underwater profile.

According to the modeling data it was obtained that mainly the decrease in sediment transport towards the sea occurs for waves that do not break above the bar (Fig. 4).

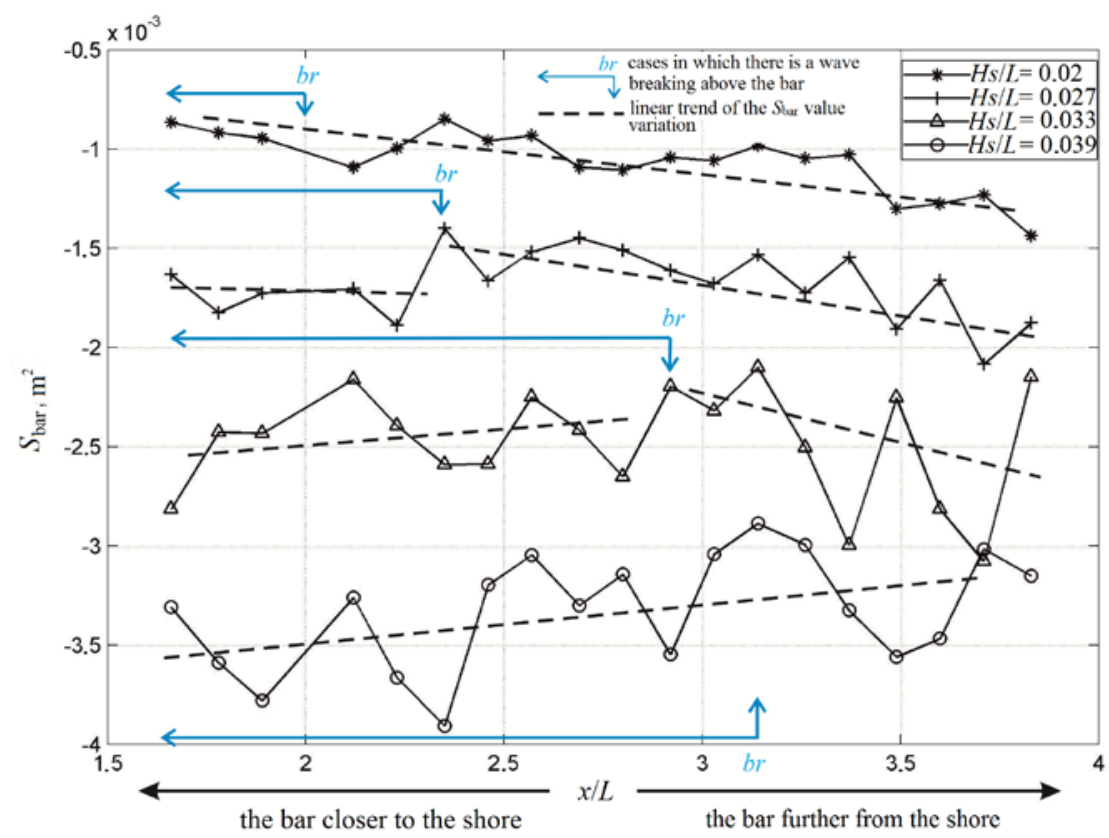

Fig. 4. Dependence of the values of the total sediment transport upon the relative distance of the bar from the coast $(x / L)$

For the gentle waves (with 0.02 initial steepness) propagating above the underwater bar, the decrease in sediment transport towards the sea is observed for both breaking and non-breaking waves. The closer the underwater bar is to the coast, the less sediment transport towards the sea will take place. For the considered cases with a decrease in the bar distance from the coast $(x / L$ varies from 3.8 to 1.7$)$ the sediment consumption decreases almost twofold. For steep waves, the amount of sediments transported towards the sea will be higher for breaking waves. Moreover, the closer the bar is to the coast, the greater is the sediment transport towards the sea. For the waves with initial steepness of 0.039 the amount of sediments transported towards the sea will increase in case of closer bar location relative to the coast, regardless of whether the waves break above the bar or not. 
Additional relative parameters were introduced: $S_{\mathrm{bar}} / S_{0}$ and $D R_{\mathrm{bar}} / D R_{0}$. The first parameter characterizes the relation of sediment consumption between the bar and the coastline to the sediment consumption on the profile without the underwater bar. The second parameter is a relation of energy dissipation above the bar to the total energy dissipation above the profile without the underwater bar.

The analysis of wave energy dissipation intensity revealed that the more wave energy is spent above the bar ( $D R_{\mathrm{bar}} / D R_{0}$ parameter has higher values), the smaller relative values of sediment transport are (smaller $S_{\text {bar }} / S_{0}$ values indicate a positive bar effect on the sediment transport, i. e. on the consumption decrease (Fig. 5, a)). Thus, regardless of the initial steepness of the waves, the efficiency of deepened bar (for reduction of the sediment flow towards the sea) also depends on the relative share of wave energy that dissipates when the waves pass over the underwater bar.

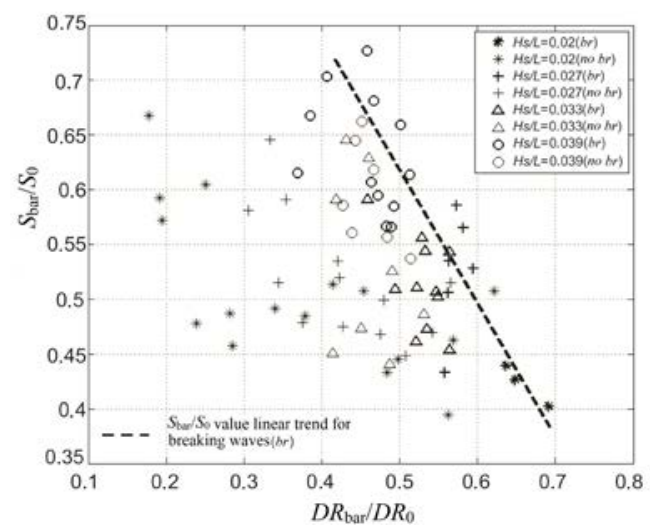

$a$

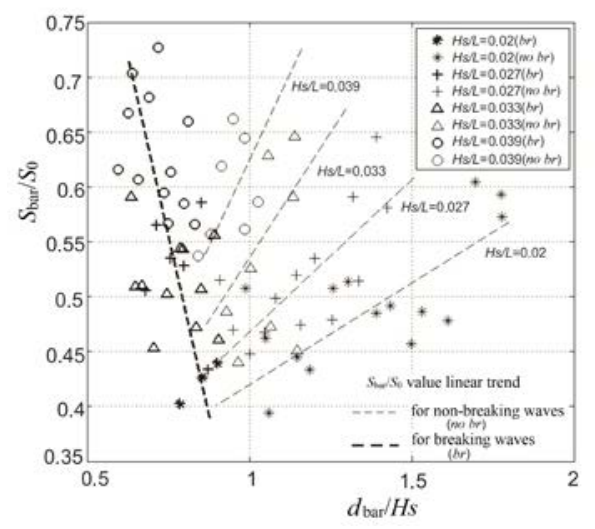

b

Fig. 5. Dependence of the relative values of the sediment transport upon the roller energy relative dissipation $(a)$ and the bar relative deepening $(b)$. Index of the «br» legend is referred to the cases of wave breaking over the bar; index of the «no br» legend is referred to the cases of no wave breaking over the bar

In its turn, the intensity of wave energy dissipation depends on the relative deepening $\left(d_{\mathrm{bar}} / H s\right)$. For all wave steepness values the minimum one of sediment consumption is observed at $d_{\mathrm{bar}} / H s \sim 0.8-0.9$, which corresponds to the waves on the verge of breaking (Fig. 5, b). For non-breaking waves the value of sediment consumption, according to the obtained trend of $S_{\mathrm{bar}} / S_{0}$ values, is linearly dependent on the relative bar depth and steepness of waves. The control of sediment transport parameters (particularly, the consumption) and the forecast of its values is possible if the waves propagate above the bar without breaking.

\section{Conclusions.}

1. It was revealed that underwater structure in the form of impermeable bar contributes to the reduction of sediment consumption towards the sea. The losses and redistribution of wave energy, when the wave passes above the bar, lead to decrease in sediment transport intensity and sediment resulting transport in the water edge zone. 
2. When the underwater bar is located closer to the coast, sediment transport towards the sea decreases for gentle waves and increases for steep ones. If the bar is located in such a way that the waves do not break above it, then the closer the bar is located to the coast, the less is the sediment consumption towards the sea.

3. Minimization of sediment consumption towards the sea is possible if the underwater bar is placed in such a way that the waves pass over it on the verge of breaking but do not break. Under this condition the bar location is optimal from the point of view of saving the sediments within the coastal zone.

\section{REFERENCES}

1. Ranasinghe, R. and Turner, I.L., 2006. Shoreline Response to Submerged Structures: A Review. Coastal Engineering, [e-journal] 53(1), pp. 65-79. doi:10.1016/j.coastaleng.2005.08.003

2. Funakoshi, H., Siozawa, T., Tadokoro, A. and Tsuda, S., 1994. Drifting Characteristics of Littoral Sand around Submerged Breakwater (Field Survey on Niigata West Coast). In: Port and Harbour Research Institute, 1994. Proceedings of the International Conference on HydroTechnical Engineering for Port and Harbor Construction "HYDRO-PORT '94", October 19-21, 1994, Yokosuka, Japan. Yokosuka, Japan: Port and Harbour Research Institute, Ministry of Transport. Vol. 2, pp. 1157-1178.

3. Hirose, N., Watanuki, A. and Saito, M., 2002. New Type Units for Artificial Reef Development of Eco-Friendly Artificial Reefs and the Effectiveness Thereof. In: R. J. Cox. Sydney, ed., 2002. 30th PIANC-AIPCN Congress 2002. N.S.W.: Institution of Engineers, pp. 886-899. Available at: https://search.informit.com.au/documentSummary;dn=693769661061571;res=IELENG [Accessed: 26 September 2018].

4. Van der Meer, J.M., Regeling, E. and de Waal, J.P., 2000. Wave Transmission: Spectral Changes and its Effects on Run-Up and Overtopping. In: B. L. Edge, ed., 2000. Coastal Engineering. Sydney: ASCE. Vol. 1, pp. 2156-2168. doi:10.1061/40549(276)168

5. Carevic, D., Loncar, G. and Prsic, M., 2012. Transformation of Statistical and Spectral Wave Periods Crossing a Smooth Low-Crested Structure. Oceanologia, [e-journal] 54(1), pp. 39-58. doi:10.5697/oc.54-1.039

6. Kovalenko, A.N. and Korzinin, D.V., 2015. Transformatsiya Voln nad Podvodnym Volnolomom so Znachitel"nym Zaglubleniem [Wave Transformation under Submerged Breakwater with Significant Deepening]. Transport Construction, (10), pp. 2-6 (in Russian).

7. Saprykina, Y., Kuznetsov, S. and Korzinin, D. 2015. Nonlinear Transformation of Waves above Submerged Structures. Procedia Engineering, [e-journal] 116, pp. 187-194. https://doi.org/10.1016/j.proeng.2015.08.281

8. Korzinin, D., 2016. Parametrization of Wave Transformation above Submerged Bar Based on Physical and Numerical Tests. In: University of Ottawa, 2016. Proceedings of the 6th International Conference on the Application of Physical Modelling in Coastal and Port Engineering and Science (Coastlab16). Ottawa, Canada, 10-13 May, 2016. Ottawa: University of Ottawa. Available at: http://rdio.rdc.uottawa.ca/publications/coastlab16/coastlab27.pdf [Accessed: 26 September 2018].

9. Korzinin, D.V., 2017. Transformatsiya Voln nad Pogruzhennym Barom po dannym Fizicheskogo i Matematicheskogo Modelirovaniya [Transformation of Waves on the Downloaded Ledge Using Physical and Mathematical Assimulation]. In: MHI, 2017. Ekologicheskaya Bezopasnost' Pribrezhnoy i Shel'fovoy Zon Morya [Ecological Safety of Coastal and Shelf Zones of Sea]. Sevastopol: ECOSI-Gidrofizika. Iss. 4, pp. 14-21.

10. Roelvink, D., Reniers, A., van Dongeren, A., van Thiel de Vries, J., McCall, R. and Lescinski, J., 2009. Modelling Storm Impacts on Beaches, Dunes and Barrier Islands. Coastal Engineering, [e-journal] 56(11-12), pp. 1133-1152. https://doi.org/10.1016/j.coastaleng.2009.08.006

11. Grunnet, N.M., Walstra, D-J.R. and Ruessink, B.G., 2004. Process-Based Modelling of a Shoreface Nourishment. Coastal Engineering, 51(7), pp. 581-607. 
12. Galappatti, G. and Vreugdenhil, C.B., 1985. A depth-Integrated Model for Suspended Transport. Journal of Hydraulic Research, [e-journal] 23(4), pp. 359-377. doi:10.1080/00221688509499345

13. Soulsby, R.L., 1997. Dynamics of Marine Sands: A Manual for Practical Applications. London: Thomas Telford, 249 p.

14. Saprykina, Ya.V., Korzinin, D.V., Shtremel, M.N., Divinsky, B.V., Kuznetsova, O.A. and Kovalenko, A.N., 2018. Transformatsiya Voln nad Osobennostyami Podvodnogo Rel'efa Dna $v$ Primenenii $k$ Metodam Zashchity Beregov [Wave Transformation over the Peculiarities of Underwater Relief in Application to Shore Protection]. Moscow: Onebook.ru, 164 p. (in Russian).

15. Battjes, J.A. and Stive, M.J.F., 1985. Calibration and Verification of a Dissipation Model for Random Breaking Waves. Journal of Geophysical Research, [e-journal] 90(C5), pp. 9159-9167. https://doi.org/10.1029/JC090iC05p09159

About the authors:

Dmitry V. Korzinin - Research Associate, Shirshov Institute of Oceanology of RAS (36, Nakhimovsky Prospekt, Moscow, 117997, Russian Federation), Ph.D. (Geogr.), ResearcherID: A-5093-2017, Scopus Author ID: $\mathbf{5 6 8 2 9 5 6 4 8 0 0}$

Yana V. Saprykina - Senior Research Associate, Shirshov Institute of Oceanology of RAS (36, Nakhimovsky Prospekt, Moscow, 117997, Russian Federation), Ph.D. (Phys.-Math.), ORCID ID: 0000-0003-0357-0773, ResearcherID: F-7556-2014, Scopus AuthorID: 6507942096, saprykina@ocean.ru

Contribution of the co-authors:

Dmitry V. Korzinin - the research concept development, the preparation of initial data on the bottom topography, implementation of modeling in the Xbeach program, formulation of conclusions

Yana V. Saprykina - the preparation of initial data on the studied wave regimes, interpretation of intermediate and final results

All the authors have read and approved the final manuscript.

The authors declare that they have no conflict of interest. 